Hussain A Obaidi BDS, MSc, (Prof)

\section{Ali R Al-Khatib}

BDS, MSc (Assist Lect)
Comparison of Dental Arch Parameters of Three Degree of Anterior Crowding of Class I Malocclusion

\author{
Dept of Pedod, orthod, and Prev Dentistry \\ College of Dentistry, University of Mosul \\ Dept of Pedod, orthod, and Prev Dentistry \\ College of Dentistry, University of Mosul
}

\begin{abstract}
Aim: To assess the relation between the anterior dental crowding in Class I molar occlusion with the dental arch parameters in both dental arches and for both sexes. Materials and Methods: This study presented data from examination of the study casts for a sample of 106 maxillary and 142 mandibular dental arches of pupils of the intermediate school in Mosul City aged 12-15 years of Iraqi origin. The sample was divided into three main groups according to anterior dental crowding degree $(0-2.0 \mathrm{~mm}$, 2.1-4 mm and over $4.0 \mathrm{~mm}$ ). This was done by calculation of dental arch space available (dental arch perimeter) by utilizing the segment arch technique. The six segment technique assessed by using a modified sliding caliper gauge. The mesio-distal crown width of each tooth was measured, to get the space necessary, and the difference between the space available and the space necessary is negative value represent the amount of crowding. The data was analyzed utilizing statistical analyses at $p \leq 0.05$ significant level. Results: all the dental arch parameters were insignificantly decreased throughout the three groups accompanied by increase in the degree of anterior dental crowding except the dental arch perimeter which decreased significantly, while intercanine and the canine-molar parameters were insignificantly increased in both dental arches and for both sexes. Conclusion: The inter-canine parameter increase in crowding case whereas the other parameters are decrease.
\end{abstract}

Key Words: Class I malocclusion, crowding, Dental arch parameters.

Obaidi HA, Al-Khatib AR. Comparison of Dental Arch Parameters of Three Degree of Anterior Crowding of Class I Malocclusion. Al-Rafidain Dent J. 2006; 6(Sp Iss ): 48S-57S.

Received: $17 / 4 / 2005$

Accepted for Publication: 31/5/2005

\section{INTRODUCTION}

Anterior dental crowding is one of the most common and recognized features of malocclusion. Many thoughts and factors have been advanced to explain its nature. One of these is regarding it as a discrepancy between the mesio-distal crown width and the size of the dental arch parameterrs. ${ }^{(1,2)}$

Numerous investigations that have been undertaken to determine the causative factors in crowding. There seems to be general agreement that dental crowding is a multifactorial condition and no specific can cause it independently. ${ }^{(3)}$

Despite, Bishara $^{(4)}$ in their studies, indicated that the hereditary and environmental appeared equally important, but the hereditary was the major factor particularly in severe malocclusion.

The basal bone growth (mandible and maxilla) serve as bases for the dental arches. So any change in their morphology or growth may alter the occlusal relation and function. ${ }^{(5)}$ Furthermore, it was considered that the anterior crowding is a multifactorial problem and the skeletal pattern of growth was one of these factors. ${ }^{(6)}$ responsible factors for the forward movement of buccal teeth. ${ }^{(7)}$

The other important factors of dental arch crowding were: 1) Supernumerary teeth, ${ }^{(8)}$ 2) Early loss of primary teeth ${ }^{(8)} 3$ ) Prolong retention of primary teeth ${ }^{(9)} 4$ ) Abnormal eruptive pathway, $\left.{ }^{(9)} 5\right)$ Bad oral habits, ${ }^{(10,11)}$ and 6) Mouth breathing. ${ }^{(6,12)}$

This study is an attempt to describe the influence of the three degree of anterior dental crowding (0-2.0 mm, 2.1-4.0 $\mathrm{mm}$ and over $4.0 \mathrm{~mm}$ ) on the dental arch parameters (intercanine, interpremolar, intermolar, canine-vertical, molar-vertical, 
canine-molar, incisal-canine, incisal-molar and arch perimeter) in both dental arches and for both sexes.

\section{MATERIALS AND METHODS}

The sample was collected from the intermediate school pupils of age range between 12-15 years in Mosul city. The clinical examination of 8932 pupils provided 106 maxillary and 142 mandibular cases of anterior dental crowding. The sample was divided into three groups according to the degree of the anterior crowding as follows:

Group A (0.1-2 mm crowding): For male was 20 maxillary arches and 35 mandibular arches and for female was 21 maxillary arches and 21 mandibular arches.

Group B (2.1-4.0 mm crowding): For male was 17 maxillary arches and 26 mandibular arches and for female was 12 maxillary arches and 26 mandibular arches.

Group C (4.1 mm and over): For male was 20 maxillary arches and 12 mandibular arches and for female was 16 maxillary arches and 14 mandibular arches.

The selected sample was fulfilled the following criteria: Normal healthy pupil of Iaqi origin without any facial deformity or asymmetry; full complement of permanent dentition excluding the second and third mlars; all teeth were normal in shape and fully erupted; the sample of Class I occlusion according to Angle's classification; ${ }^{(13)}$ no history of any previous orthodontic treatment and no history of any oral habits.

The conducted methods in this study included: Precise alginate impressions were taken for the selected anterior crowding dental arches, and good stone casts were prepared to measure: Anterior crowding in millimeter as described by Hunter and Priest $^{(14)}$ and Hunter ${ }^{(15)}$ in measuring the dental arch space necessary (summation the mesiodistal crown width).

The space available, which was measured according to that of Lundstrom. ${ }^{(16)}$ This was measured in six segments in each dental arch, and the summation of these six segment measurements gave dental arch perimeter. The amount of the crowding was derived by the formula: Dental arch space available - dental arch space necess- ary $=$ amount of dental crowding (negative in value). The dental casts were divided into three groups according to the amount of crowding, which were $0.1-2 \mathrm{~mm}, 2.1-4$ $\mathrm{mm}$ and $4.1 \mathrm{~mm}$ and over. The dental arches parameters were measured from the dental arch study cast.

These parameters were: Intercanine distance, Intermolar distance at mesiobuccal cusp tip (ICD, IMD) ${ }^{(17)}$, Interpremolar distance (OPD) ${ }^{(18)}$, Canine vertical distance $(\mathrm{CVD})^{(19)}$, Molar vertical distance at mesiobuccal cusp tip (MVD) ${ }^{(20)}$ Right canine-molar distance Left canine-molar distance, (CMD-R, CMD-L) ${ }^{(21)}$, Right incisor-canine distance Left incisor-canine distance, (InCD-R, InCD-L) ${ }^{(22)}$, Right incisor-molar distance, Left incisor-molar distance (InMD-R, InMD-L) ${ }^{(23)}$, Arch perimeter $(\mathrm{AP})^{(16)}$

The study sample data were subjected to the statistical analysis, which included: Descriptive analyses (mean and standard deviation), One-way analysis of variance (ANOVA test) and Multiple compression test (modified $\mathrm{t}$-test) at $p<0.05$ for various dental arch parameters and the crowding degree.

\section{RESULTS}

The analysis of the variance (Tables 1 and 2) revealed no significant difference in the dental arch parameters among the three groups of anterior crowding for both sexes in the maxillary dental arch and also in mandibular dental arch, except that the dental arch perimeter had significant differences among the three groups of anterior crowding in maxillary and mandibular dental arches for both sexes.

The application of the variance analysis at $p<0.05$, a significant difference was noticed in dental arch parameters between male and female for both maxillary and mandibular dental arches (Table 3) and (Figure 1).

The analysis of variance (at $p<0.05$ ) explored no significant difference between the piled right and left parameters of the (incisal-canine, incisal-molar and caninemolar) in both dental arches for both sexes as illustrated in (Table 4) and (Figure 2) 
Table (1): Comparison among the means for the maxillary and the mandibular dental arch dimensions of the crowded anterior teeth in males

\begin{tabular}{|c|c|c|c|c|c|c|}
\hline \multirow{4}{*}{$\begin{array}{c}\text { Dental } \\
\text { Arch } \\
\text { Dimensions }\end{array}$} & \multirow{4}{*}{ Side } & \multicolumn{3}{|c|}{ Anterior Crowding Degree } & \multirow{3}{*}{$\begin{array}{l}\text { Pooled } \\
\text { NU=57 } \\
\text { NL=73 } \\
\end{array}$} & \multirow{4}{*}{ F-Value } \\
\hline & & $0.1-2 \mathrm{~mm}$ & $2.1-4.0 \mathrm{~mm}$ & $\geq 4.1 \mathrm{~mm}$ & & \\
\hline & & $\begin{array}{l}\mathrm{NU}=20 \\
\mathrm{NL}=35\end{array}$ & $\begin{array}{l}\mathrm{NU}=17 \\
\mathrm{NL}=26\end{array}$ & $\begin{array}{l}\mathrm{NU}=20 \\
\mathrm{NL}=12\end{array}$ & & \\
\hline & & Mean \pm SD & Mean \pm SD & Mean \pm SD & Mean \pm SD & \\
\hline \multicolumn{7}{|c|}{ Maxillary Dental Arch } \\
\hline ICD & & $34.29 \pm 3.98$ & $34.77 \pm 2.51$ & $34.92 \pm 1.40$ & $34.61 \pm 2.52$ & Not significant \\
\hline IPD & & $47.24 \pm 1.63$ & $46.91 \pm 1.97$ & $45.84 \pm 1.65$ & $46.04 \underline{2} .61$ & Not significant \\
\hline IMD & & $51.52 \pm 2.42$ & $50.12 \pm 1.48$ & $48.92 \pm 1.63$ & $50.62 \pm 2.49$ & Not significant \\
\hline C-VD & & $8.63 \pm 1.33$ & $8.44 \pm 1.19$ & $8.31 \pm 0.99$ & $8.47 \pm 1.37$ & Not significant \\
\hline M-VD & & $31.65 \pm 1.29$ & $31.32 \pm 0.74$ & $31.20 \pm 0.99$ & $31.47 \pm 1.14$ & Not significant \\
\hline \multirow{2}{*}{ In-CD } & Right & $19.0 \pm 1.29$ & $18.71 \pm 1.47$ & $17.72 \pm 2.76$ & $18.64 \pm 2.83$ & Not significant \\
\hline & Left & $18.88 \pm 1.00$ & $18.42 \pm 1.74$ & $18.23 \pm 2.26$ & $18.59 \pm 2.19$ & Not significant \\
\hline \multirow{2}{*}{ In-MD } & Right & $41.08 \pm 2.12$ & $40.54 \pm 1.81$ & $39.46 \pm 2.69$ & $41.88 \pm 1.66$ & Not significant \\
\hline & Left & $41.53 \pm 2.21$ & $40.47 \pm 1.76$ & $40.15 \pm 2.65$ & $42.07 \pm 1.53$ & Not significant \\
\hline \multirow{2}{*}{ C-MD } & Right & $26.23 \pm 0.82$ & $26.68 \pm 0.44$ & $26.75 \pm 1.25$ & $25.78 \pm 1.29$ & Not significant \\
\hline & Left & $26.10 \pm 1.06$ & $26.25 \pm 0.70$ & $26.81 \pm 0.88$ & $26.41 \pm 1.66$ & Not significant \\
\hline $\mathbf{A P}$ & & $97.75 \pm 3.23$ & $96.15 \pm 2.73$ & $91.61 \pm 4.16$ & $94.71 \pm 4.27$ & Significant \\
\hline \multicolumn{7}{|c|}{ Mandibular Dental Arch } \\
\hline ICD & & $26.50 \pm 2.09$ & $26.66 \pm 2.37$ & $26.86 \pm 2.29$ & $26.59 \pm 2.30$ & Not significant \\
\hline IPD & & $39.89 \pm 1.73$ & $39.46 \pm 1.95$ & $38.40 \pm 2.66$ & $39.44 \pm 2.18$ & Not significant \\
\hline IMD & & $44.23 \pm 2.56$ & $43.85 \pm 1.68$ & $43.36 \pm 1.73$ & $43.90 \pm 2.03$ & Not significant \\
\hline C-VD & & $5.84 \pm 0.91$ & $5.52 \pm 1.18$ & $4.99 \pm 1.12$ & $5.63 \pm 3.09$ & Not significant \\
\hline M-VD & & $26.52 \pm 2.40$ & $26.36 \pm 1.31$ & $26.10 \pm 1.73$ & $26.40 \pm 2.08$ & Not significant \\
\hline \multirow{2}{*}{ In-CD } & Right & $13.27 \pm 1.13$ & $12.58 \pm 2.31$ & $12.48 \pm 2.26$ & $13.04 \pm 1.35$ & Not significant \\
\hline & Left & $13.12 \pm 1.47$ & $12.37 \pm 2.23$ & $12.21 \pm 2.66$ & $12.96 \pm 1.76$ & Not significant \\
\hline \multirow{2}{*}{ In-MD } & Right & $36.49 \pm 2.93$ & $36.29 \pm 3.29$ & $35.98 \pm 3.03$ & $36.38 \pm 1.93$ & Not significant \\
\hline & Left & $36.41 \pm 3.75$ & $36.29 \pm 3.29$ & $35.93 \pm 2.76$ & $36.29 \pm 1.09$ & Not significant \\
\hline \multirow{2}{*}{ C-MD } & Right & $25.68 \pm 0.85$ & $25.91 \pm 0.93$ & $26.21 \pm 1.01$ & $25.85 \pm 1.01$ & Not significant \\
\hline & Left & $25.55 \pm 0.96$ & $25.83 \pm 1.66$ & $26.06 \pm 1.18$ & $25.78 \pm 1.01$ & Not significant \\
\hline $\mathbf{A P}$ & & $85.32+4.01$ & $83.63+3.95$ & $80.71 \pm 3.33$ & $34.35 \pm 3.74$ & Significant \\
\hline
\end{tabular}

All measurements are in mm; N: Number; U: upper; L: Lowe; ICD: Intercanine distance; IPD: Interpremolar distance; IMD: Intermolar distance at mesiobuccal cusp tip; CVD: Canine vertical distance; MVD: Molar vertical distance at mesiobuccal cusp tip; CMD: Canine-molar distance; InCD: Incisor-canine distance; InMD: Incisor-molar distance; AP: Arch perimeter.

Dental arch parameter 
Table (2): Comparison among the means for the maxillary and the mandibular dental arch dimensions of the crowded anterior teeth in females

\begin{tabular}{|c|c|c|c|c|c|c|c|c|c|c|}
\hline \multirow{4}{*}{$\begin{array}{l}\text { Dental Arch } \\
\text { Dimensions }\end{array}$} & \multirow{4}{*}{ Side } & \multicolumn{6}{|c|}{ Anterior Crowding Degree } & \multirow{2}{*}{\multicolumn{2}{|c|}{ Pooled }} & \multirow{4}{*}{ F-Value } \\
\hline & & \multirow{2}{*}{\multicolumn{2}{|c|}{$\begin{array}{c}0.1-2 ~ m m \\
N U=21 \\
N L=29\end{array}$}} & \multirow{2}{*}{\multicolumn{2}{|c|}{$\begin{array}{c}2.1-4.0 \mathrm{~mm} \\
\mathrm{NU}=12 \\
\mathrm{NL}=26\end{array}$}} & \multirow{2}{*}{\multicolumn{2}{|c|}{$\begin{array}{c}\geq 4.1 \mathrm{~mm} \\
\mathrm{NU}=16 \\
\mathrm{NL}=14\end{array}$}} & & & \\
\hline & & & & & & & & \multicolumn{2}{|c|}{$\begin{array}{l}\mathrm{NU}=49 \\
\mathrm{NL}=69\end{array}$} & \\
\hline & & Mean & $+\mathrm{SD}$ & Mean & $+\mathrm{SD}$ & Mean & $+\mathrm{SD}$ & Mean & $+\mathrm{SD}$ & \\
\hline \multicolumn{11}{|c|}{ Maxillary Dental Arch } \\
\hline ICD & & 32.62 & 2.71 & 33.07 & 1.25 & 33.14 & 4.09 & 32.65 & 4.09 & ficant \\
\hline IPD & & 44.98 & 1.86 & 44.61 & 1.03 & 43.24 & 3.31 & & 2.24 & ícant \\
\hline IMD & & 49.51 & 2.56 & 49.27 & 1.51 & 48.77 & 3.29 & & & iificant \\
\hline C-VD & & 7.69 & 1.29 & 7.67 & 1.5 & 7.52 & 1 . & 7.64 & & ificant \\
\hline M-VD & & 29.71 & 2.98 & 29.64 & 1.92 & 29.13 & 3. & 19 & & Not \\
\hline \multirow{2}{*}{ In-CD } & Right & 18.02 & 1.98 & 17.83 & 0.68 & 17.70 & 1.98 & 17.90 & & nificant \\
\hline & Left & 17.98 & 2.22 & 17.72 & 1.25 & 17.39 & 2.22 & 17.73 & 1 & icant \\
\hline \multirow{2}{*}{ In-MD } & Right & 40.21 & 1.14 & 39.50 & 1.18 & 39.12 & 2.45 & 39.64 & 1 . & ficant \\
\hline & Left & 40.72 & 1.98 & 39.83 & 1.26 & 39.96 & 2.43 & 40.28 & 1. & îcant \\
\hline \multirow{2}{*}{ C-MD } & Right & 25.14 & 1.22 & 25.25 & 1.63 & 25.31 & 1.57 & 25.15 & 3.29 & ificant \\
\hline & Lef & 25.05 & 1.18 & 25.33 & 1.03 & 25.41 & 1.11 & 25.02 & 3.39 & nificant \\
\hline $\mathbf{A P}$ & & 90.28 & 4.48 & 89.25 & 5.31 & 87.73 & 3.72 & 88.95 & 4.2 & \\
\hline \multicolumn{11}{|c|}{ Mandibular Dental Arch } \\
\hline ICD & & 25.17 & 2.61 & 25.42 & 2.63 & 24.75 & 2.02 & 25.23 & 1.73 & ficant \\
\hline IPD & & 38.21 & 1.55 & 38.08 & 2.42 & 37.25 & 1.8 & 37.93 & 1.97 & ificant \\
\hline IMD & & 43.20 & 2.69 & 42.70 & 2.94 & 42.35 & 1.8 & 42.84 & 2.20 & nificant \\
\hline $\mathrm{C}-\mathrm{VD}$ & & 4.96 & 0.82 & 4.68 & 1.41 & 4.42 & 0.90 & 4.76 & 1.06 & Not significant \\
\hline M-VD & & 25.39 & 0.75 & 25.28 & 2.53 & 24.57 & 1.08 & 24.96 & 2.05 & Not significant \\
\hline \multirow{2}{*}{ In-CD } & Right & 13.41 & 1.81 & 12.82 & 1.29 & 12.70 & 1.02 & 12.89 & 3.88 & Not significant \\
\hline & Left & 13.46 & 2.28 & 12.68 & 1.55 & 12.44 & 1.03 & 12.75 & 4.01 & Not significant \\
\hline \multirow{2}{*}{ In-MD } & Right & 35.13 & 1.02 & 35.06 & 1.98 & 34.77 & 1.41 & 34.92 & 2.99 & Not significant \\
\hline & Left & 35.20 & 1.39 & 35.15 & 2.28 & 34.90 & 1.19 & 35.23 & 2.25 & Not significant \\
\hline \multirow{2}{*}{ C-MD } & Right & 25.26 & 0.64 & 25.48 & 1.06 & 25.95 & 0.88 & 24.52 & 1.88 & Not significant \\
\hline & Light & 25.34 & 0.80 & 25.45 & 1.06 & 26.13 & 0.96 & 25.08 & 1.36 & Not significant \\
\hline $\mathbf{A P}$ & & 84.75 & 4.77 & 82.72 & 4.50 & 80.79 & 2.63 & 81.87 & 4.34 & Significant \\
\hline
\end{tabular}

All measurements are in $\mathrm{mm}$; N: Number; U: upper; L: Lowe; ICD: Intercanine distance; IPD: Interpremolar distance; IMD: Intermolar distance at mesiobuccal cusp tip; CVD: Canine vertical distance; MVD: Molar vertical distance at mesiobuccal cusp tip; CMD: Canine-molar distance; InCD: Incisor-canine distance; InMD: Incisor-molar distance; AP: Arch perimeter. 
Table (3): Comparison of the means for the maxillary and the mandibular dental arch dimensions of the crowded anterior teeth between males and females

\begin{tabular}{|c|c|c|c|c|c|c|c|c|}
\hline \multirow[t]{2}{*}{$\begin{array}{l}\text { Dental Arch } \\
\text { Dimensions }\end{array}$} & \multirow[t]{2}{*}{ Side } & \multicolumn{2}{|c|}{$\begin{array}{c}\text { Male } \\
\text { NU }=57 \\
\text { NL }=73\end{array}$} & \multicolumn{2}{|c|}{$\begin{array}{l}\text { Female } \\
N U=49 \\
N L=69\end{array}$} & \multicolumn{2}{|c|}{$\begin{array}{c}\text { Pooled } \\
\text { NU }=106 \\
\text { NL }=142\end{array}$} & \multirow[t]{2}{*}{ t-value } \\
\hline & & Mean & \pm SD & Mean & \pm SD & Mean & \pm SD & \\
\hline \multicolumn{9}{|c|}{ Maxillary Dental Arch } \\
\hline ICD & & 34.61 & 2.52 & 32.65 & 4.09 & 33.80 & 3.34 & Significant \\
\hline IPD & & 46.04 & 2.61 & 44.28 & 2.24 & 45.31 & 2.44 & Significant \\
\hline IMD & & 50.62 & 2.49 & 49.51 & 2.21 & 50.17 & 2.33 & Significant \\
\hline C-VD & & 8.47 & 1.37 & 7.64 & 1.41 & 8.12 & 1.39 & Significant \\
\hline 3M-VD & & 31.47 & 1.14 & 29.49 & 2.32 & 30.65 & 1.79 & Significant \\
\hline \multirow{2}{*}{ In-CD } & Right & 18.64 & 2.83 & 17.90 & 1.66 & 18.36 & 3.24 & Significant \\
\hline & Left & 18.59 & 2.19 & 17.73 & 1.59 & 18.23 & 1.93 & Significant \\
\hline \multirow{2}{*}{ In-MD } & Right & 41.88 & 1.66 & 39.64 & 1.33 & 40.95 & 1.88 & Significant \\
\hline & Left & 42.07 & 1.53 & 40.28 & 1.63 & 41.33 & 2.18 & Significant \\
\hline \multirow{2}{*}{ C-MD } & Right & 25.78 & 1.29 & 25.15 & 3.29 & 25.52 & 1.97 & Significant \\
\hline & Left & 26.41 & 1.66 & 25.02 & 3.39 & 25.83 & 1.88 & Significant \\
\hline AP & & 94.71 & 4.27 & 88.95 & 4.28 & 92.31 & 4.27 & Significant \\
\hline \multicolumn{9}{|c|}{ Mandibular Dental Arch } \\
\hline ICD & & 26.59 & 2.30 & 25.23 & 1.73 & 25.91 & 1.28 & Significant \\
\hline IPD & & 39.44 & 2.18 & 37.93 & 1.97 & 38.71 & 2.07 & Significant \\
\hline IMD & & 43.90 & 2.03 & 43.84 & 2.20 & 43.38 & 2.12 & Significant \\
\hline C-VD & & 5.63 & 3.09 & 4.76 & 1.06 & 5.21 & 2.27 & Significant \\
\hline M-VD & & 26.40 & 2.08 & 24.96 & 2.05 & 25.70 & 2.04 & Significant \\
\hline \multirow{2}{*}{ In-CD } & Right & 13.04 & 1.35 & 12.89 & 3.88 & 12.97 & 2.85 & Significant \\
\hline & Left & 12.96 & 1.76 & 12.75 & 4.01 & 12.86 & 3.05 & Significant \\
\hline \multirow{2}{*}{ In-MD } & Right & 36.38 & 1.93 & 34.92 & 2.99 & 35.67 & 2.32 & Significant \\
\hline & Left & 36.29 & 1.09 & 35.23 & 2.25 & 35.76 & 1.32 & Significant \\
\hline \multirow{2}{*}{ C-MD } & Right & 25.85 & 1.01 & 24.52 & 1.88 & 25.16 & 1.53 & Significant \\
\hline & Left & 25.78 & 1.01 & 25.08 & 1.36 & 25.43 & 1.32 & Significant \\
\hline AP & & 84.35 & 3.74 & 81.87 & 4.34 & 83.14 & 3.92 & Significant \\
\hline
\end{tabular}

All measurements are in mm; N: Number; U: upper; L: Lowe; ICD: Intercanine distance; IPD: Interpremolar distance; IMD: Intermolar distance at mesiobuccal cusp tip; CVD: Canine vertical distance; MVD: Molar vertical distance at mesiobuccal cusp tip; CMD: Canine-molar distance; InCD: Incisor-canine distance; InMD: Incisor-molar distance; AP: Arch perimeter. 
- $0.1-2 \mathrm{~mm}$ $2.1-4.0 \mathrm{~mm}$ 口 $>4.1 \mathrm{~mm}$

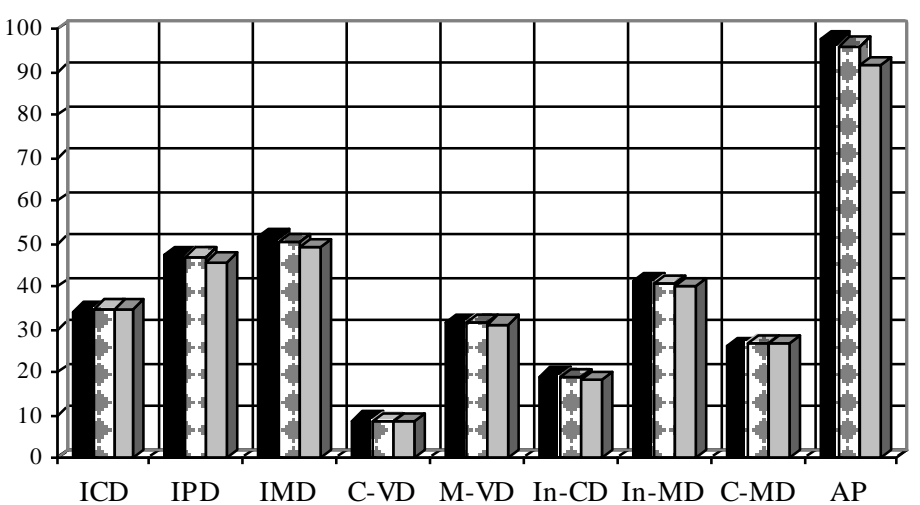

(A)

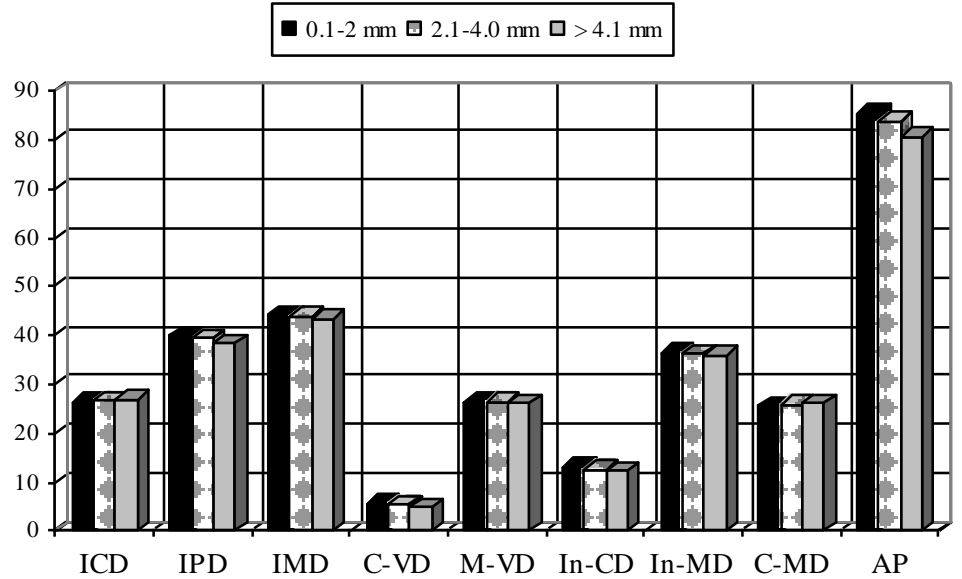

(B)

Figure (1): Means for the maxillary. A: and mandibular; B: dental arch dimensions of the crowded anterior teeth in males

Table (4): Comparison of the means for the maxillary and the mandibular dental arch dimensions of the crowded anterior teeth between the right and left sides for both sexes

\begin{tabular}{|c|c|c|c|c|c|c|c|}
\hline \multirow{2}{*}{$\begin{array}{l}\text { Dental Arch } \\
\text { Dimensions }\end{array}$} & \multirow{2}{*}{ Side } & \multicolumn{2}{|c|}{ Male } & \multirow{2}{*}{ t-value } & \multicolumn{2}{|c|}{ Female } & \multirow{2}{*}{ t-value } \\
\hline & & Mean & $+\mathrm{SD}$ & & Mean & $+\mathrm{SD}$ & \\
\hline \multicolumn{8}{|c|}{ Maxillary Dental Arch } \\
\hline \multirow{2}{*}{ In-CD } & Right & 18.64 & 2.83 & \multirow{2}{*}{$\begin{array}{c}\text { Not } \\
\text { significant }\end{array}$} & 17.90 & 1.66 & \multirow{2}{*}{$\begin{array}{c}\text { Not } \\
\text { significant }\end{array}$} \\
\hline & Left & 18.59 & 2.19 & & 17.73 & 1.59 & \\
\hline \multirow{2}{*}{ In-MD } & Right & 41.88 & 1.66 & \multirow{2}{*}{$\begin{array}{c}\text { Not } \\
\text { significant }\end{array}$} & 39.64 & 1.33 & \multirow{2}{*}{$\begin{array}{c}\text { Not } \\
\text { significant }\end{array}$} \\
\hline & Left & 42.07 & 1.53 & & 40.28 & 1.63 & \\
\hline \multirow{2}{*}{ C-MD } & Right & 25.78 & 1.29 & \multirow{2}{*}{$\begin{array}{c}\text { Not } \\
\text { significant }\end{array}$} & 25.15 & 3.26 & \multirow{2}{*}{$\begin{array}{c}\text { Not } \\
\text { significant }\end{array}$} \\
\hline & Left & 26.41 & 1.66 & & 25.02 & 3.39 & \\
\hline \multicolumn{8}{|c|}{ Mandibular Dental Arch } \\
\hline \multirow{2}{*}{ In-CD } & Right & 13.14 & 1.35 & \multirow{2}{*}{$\begin{array}{c}\text { Not } \\
\text { significant }\end{array}$} & 12.89 & 3.88 & \multirow{2}{*}{$\begin{array}{c}\text { Not } \\
\text { significant }\end{array}$} \\
\hline & Left & 12.96 & 1.75 & & 12.75 & 4.01 & \\
\hline \multirow{2}{*}{ In-MD } & Right & 36.38 & 1.93 & \multirow{2}{*}{$\begin{array}{c}\text { Not } \\
\text { significant }\end{array}$} & 34.92 & 2.99 & \multirow{2}{*}{$\begin{array}{c}\text { Not } \\
\text { significant }\end{array}$} \\
\hline & Left & 36.29 & 1.09 & & 35.23 & 2.25 & \\
\hline \multirow{2}{*}{ C-MD } & Right & 25.85 & 1.01 & \multirow{2}{*}{$\begin{array}{c}\text { Not } \\
\text { significant }\end{array}$} & 24.52 & 1.88 & \multirow{2}{*}{$\begin{array}{c}\text { Not } \\
\text { significant }\end{array}$} \\
\hline & Left & 25.78 & 1.01 & & 25.08 & 136 & \\
\hline
\end{tabular}

All measurements are in $\mathrm{mm}$; $\mathrm{N}$ : Number; $\mathrm{U}$ : upper; L: Lowe; ICD: Intercanine distance; IPD: Interpremolar distance; IMD: Intermolar distance at mesiobuccal cusp tip; CVD: Canine vertical distance; MVD: Molar vertical distance at mesiobuccal cusp tip; CMD: Canine-molar distance; InCD: Incisor-canine distance; InMD: Incisor-molar distance; AP: Arch perimeter. 
口 0.1-2 mm $\square 2.1-4.0 \mathrm{~mm}$ 日> $4.1 \mathrm{~mm}$

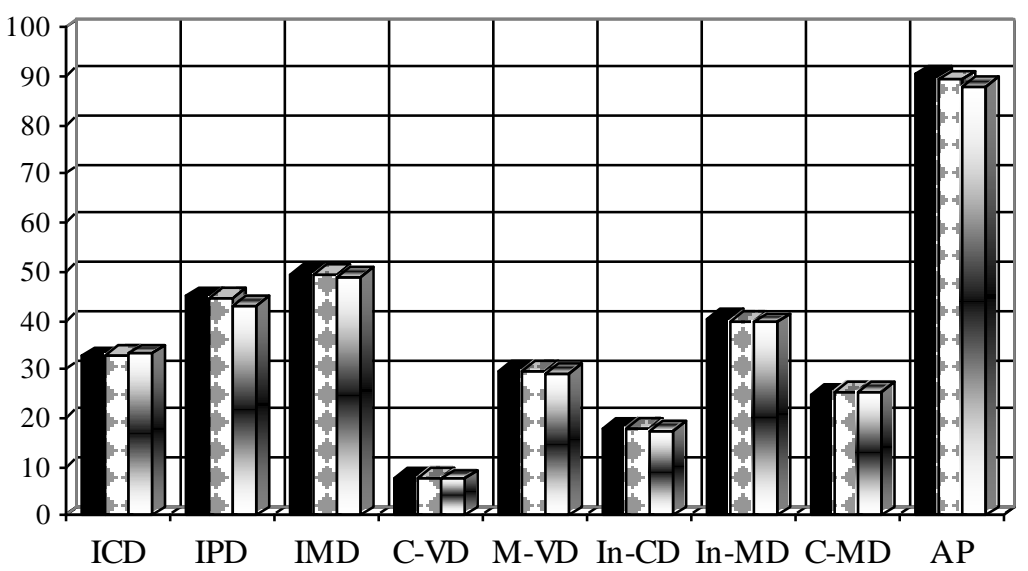

(A)

$0.1-2 \mathrm{~mm} \square 2.1-4.0 \mathrm{~mm} \square>4.1 \mathrm{~mm}$

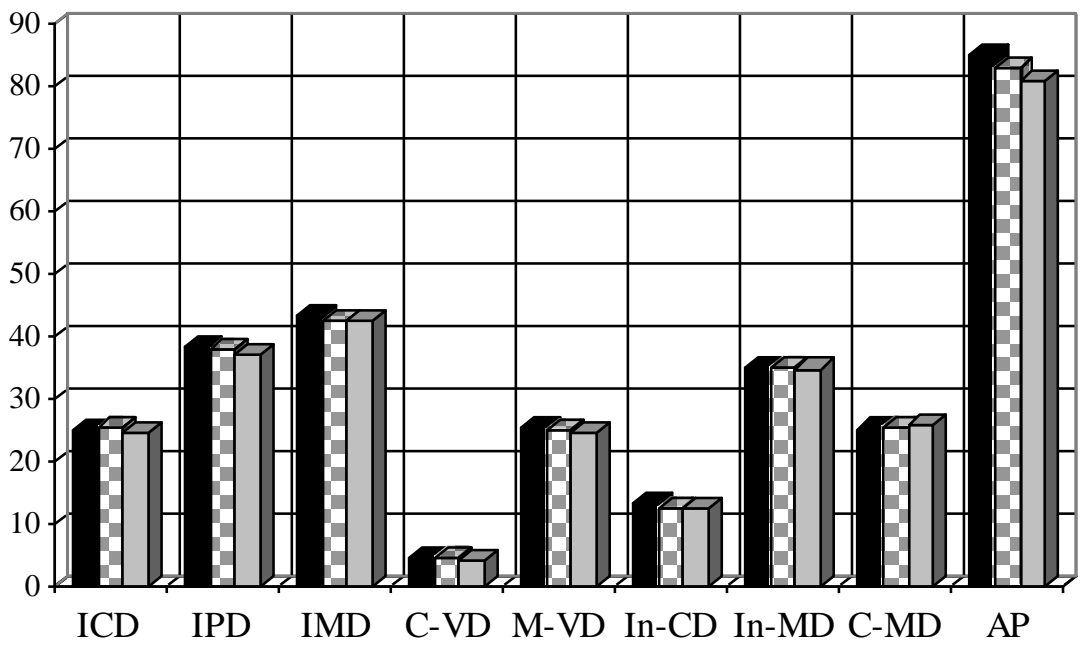

(B)

Figure (2): Means for the maxillary. A: and mandibular; B: dental arch dimensions of the crowded anterior teeth in females

\section{DISCUSSION}

There was a non significant ascending changes in the mean value of the ICD within the three groups of anterior dental crowding in the maxillary and mandibular dental arches for both sexes. This finding was similar to those of Berg, ${ }^{(24)}$ but paradoxical to those of Sinclair and Little ${ }^{(17)}$ reduction in the ICD accompanied by the increase in the anterior dental crowding. The present result disagree with the findings of Al-Hassany, ${ }^{(25)}$ who reported no change (no increase or decrease) in the mean values of the maxillary ICD in persons with anterior dental crowding, Male and female comparison revealed a significant greater mean value of the ICD in male than fe- male in both dental arches. This finding confirmed with other studies. ${ }^{(24,26)}$ The greater mean value of the ICD in male than female could be due to large dental arch of male than female.

The mean value of the IPD showed insignificant decrease among the three groups of anterior dental crowding for the maxillary and mandibular dental arches in both sexes. The insignificant decrease in the IPD in this study among the three degrees of anterior crowding indicated that the crowding had no significant influence on this parameter. Male and female comparison explored significant increase mean value of the IPD in male than female for both arches, within the three degrees of 
anterior dental crowding. This confirmed the finding of other researchers. ${ }^{(26,27)}$ The mean value of this dental parameter of the male and female for both dental arches were smaller than the result of Younes. ${ }^{(22)}$

The present study showed non significant decreasing change in the mean value of the IMD within the increase degree of anterior dental crowding in maxillary and mandibular dental arches for both sexes. This reduction in this parameter was similar to that reported by others, ${ }^{(12,26)}$ but different from that reported by Sinclair and Little $^{(17)}$ who indicated no change in this parameter accompanying the increase in the anterior dental crowding. Male and female comparison displayed that this dental arch parameter was significantly larger in male than in female for both dental arches within the three degrees of anterior dental crowding. This finding agrees with that of Sinclair and Little. ${ }^{(17)}$ The mean value of this parameter showed non significant decrease accompanied with the increase in the anterior dental crowding in both dental arches and for both sexes. This finding was in accordance with the result of Chang et $a .^{(28)}$ Male and female comparison showed a significant increase of this parameter in male than female in both arches with the three groups of crowding. This significant increase in mean value of the male than female obviously due to that male has larger dental arch than female. ${ }^{(26)}$. The mean of this distance revealed insignificant decrease accompanied increase in the anterior dental crowding within the studied groups in both dental arches and for both sexes. This result matched with that of Lavelle. ${ }^{(29)}$ Male and female comparison mean values showed that the male had significantly larger mean than female. This is due to large dental arch of male than female.

The right and left ICD was observed that there was no significant difference between them for both arches and for both sexes. These results were in accordance with that of Bishara et al. ${ }^{(30)}$

The mean MVD showed non significant reduction in both dental arches and for both sexes accompanied by the increase in the degree of anterior dental crowding. This is in accordance with the finding of Chang et al., ${ }^{(28)}$ and contrast with that rep- orted by Howes. ${ }^{(31)}$ The male and female comparison was revealed a significantly large mean value in male than female for maxillary and mandibular arches within the three groups of anterior dental arch crowding. This result was in agreement with Sinclair and Little. ${ }^{(17)}$

The mean IMD explored non significant decrease accompanied by the increase anterior dental crowding in both dental arches and for both sexes. This result was matching the finding of Turkkahraman and Sayin. ${ }^{(32)}$ The male and female comparison was observed that the male had significantly larger mean than the female for both arches within the three groups of anterior dental crowding. This result was in agreement with that of Sinclair and Little. ${ }^{(17)}$.The right and left comparison was revealed no significant difference in the mean value of the right and left IMD in both dental arches and for both sexes. This parameter showed a mean non significant increase within the increase anterior dental crowding in both dental arches and for both sexes. This finding confirms the result of Richardson, ${ }^{(33)}$ and contrast with that of Lavelle ${ }^{(23)}$ who reported a reduction in this parameter accompanied by the presence of dental crowding as they conducted their studies in samples having posterior dental crowding. The male and female compareison of this study revealed a significantly large mean of CMD in male than female in both arches within the three degrees of anterior dental crowding. This is obviously due to large dental arch in male than female.

The right and left CMD explored no significant difference between them in both arches and for both sexes within the groups of anterior dental crowding. This was in accordance with the result of Al-Sarraf, ${ }^{(23)}$ who investigated posterior dental crowding.

Dental Arch Parameter, This parameter showed a significant reduction accompanied with increase anterior dental crowding in both dental arches and for both sexes. This result was in accordance with the finding of Mohammed. ${ }^{(2)}$ The male and female comparison observed that the parameter in male was significantly larger than that of female for both dental arches and within the three groups of anterior dental 
crowding and this due to large dental arch in male than female.

\section{CONCLUSIONS}

The maxillary and mandibular dental arch parameters (widths and lengths) were insignificantly decrease except the dental arch perimeter which significantly decreease as the degree of the anterior dental crowding increase, while the ICD and CMD were insignificantly increased by sex.

There was significantly increase in dental arch parameters between male and female in both dental arches within the three groups of dental arch crowding. There was no significant difference between the right and left dental arch parameters in both dental arch within the investigated dental arch crowding.

\section{REFERENCES}

1. Richardson ME. The use of cephalometric $\mathrm{x}$-rays in developing basal bone size and its relationship to crowding. Eur Orthod Soc Rep Congr. 1967; 43: 181-190.

2. Peck S, Peck H. Crown dimensions and mandibular incisor alignment. Angle Orthod. 1972; 42: 148-153.

3. Gilmore CA, Little RN. Mandibular incisors dimensions and crowding. Am J Orthod. 1984; 86(6): 493-502.

4. Bishara SE. Textbook of Orthodontics. $1^{\text {st }}$ ed. WB Saunders Co. Philadelphia. 2001; p: 136.

5. Richardson ME. Late lower arch crowding in relation to direction of eruption. Eur $J$ Orthod. 1996; 18: 341-347.

6. Proffit WR, Fields HW. Contemporary Orthodontics. $3^{\text {rd }}$ ed. Mosby Inc. 2000; Pp: 13-15.

7. Foster TD. Textbook of Orthodontics. $2^{\text {nd }}$ ed. Blackwell Scientific Publication. 1984; Pp: 115-119, 131, 155-160.

8. Graber TM. Orthodontic Principles and Practice. $3^{\text {rd }}$ ed. WB Saunders Co. 1988; Pp: 301-313, 356, 363-377.

9. Dacosta OO, Orenuga OO. Dentofacial anomalies related to the digit sucking habit. Afr J Med Sci. 2002; 32: 167-171.

10. Germac D, Tanerb TU. Lower lip sucking habit treated with a lip bumper appliance. Angle Orthod. 2005; 75: 858-863.

11. Woodside DG, Linder-Aronson S, Stubbs D. Relationship between mandibular incisor crowding and nasal mucosal swelling.
Proc Finn Dent Soc. 1991; 87(1): $127-$ 138.

12. Abdullah NM. Occlusal features and perception: A sample of 13-17 years old adolescents. Master Thesis. University of Baghdad. 1996.

13. Angle EH. Classification of malocclusion. Dent Cosmos. 1889; 41: 248-264.

14. Hunter SW, Preist WR. Errors and discrepancies in measurement of tooth size. $J$ Dent Res. 1960; 30(2): 405-413.

15. Hunter SW. Application of analysis of crowding and spacing of the teeth. Dent Clin North Am. 1978; 22(4): 563-577.

16. Lundstrom A. An investigation of 202 pairs of twins regarding fundamental factors in the aetiology of malocclusion. $J$ Dent Res. 1949; 69: 251-264.

17. Sinclair PM, Little RM. Maturation of untreated normal occlusion. Am J Orthod. 1983; 83(2): 114-123.

18. Mills LF. Arch width, arch length and tooth size in young adult males. Angle Orthod. 1964; 31(2): 124-129.

19. Maj G. Serial extraction in Class I mixed dentition cases. Am J Orthod. 1970; 57(4): 393-398.

20. Mohammed IS. Maxillary arch dimensionns: A cross-sectional study between 9-17 years. Master Thesis. University of Baghdad. 1993.

21. Diwan R, Elahi JM. A comparative study between three ethnic groups to derive some standards for maxillary arch dimensions. J Oral Rehabil. 1990; 17: 143-148.

22. Younes SAS. Maxillary arch dimensions in Saudi and Egyptian population sample. Am J Orthod. 1984; 85(1): 83-87.

23. Al-Sarraf HA. Maxillary and mandibular dental arch dimensions in children aged 12-15 years with Class I normal occlusion: A cross-sectional study. MSc Thesis. College of Dentistry. University of Mosul. 1996.

24. Berg R. Crowding of the dental arches: A longitudinal study of the age period between 6 and 12 years. Eur J Orthod. 1986; 8: 43-49.

25. Al-Hassany ZR. Relations and alignment of the anterior teeth in Iraqi adults with Class I occlusion: Epidemiological study. MSCc Thesis. College of Dentistry. University of Baghdad. 1995.

26. Hassan AK, Najim ZN. Measurement of the mandibular dental arch in Baghdad pa- 


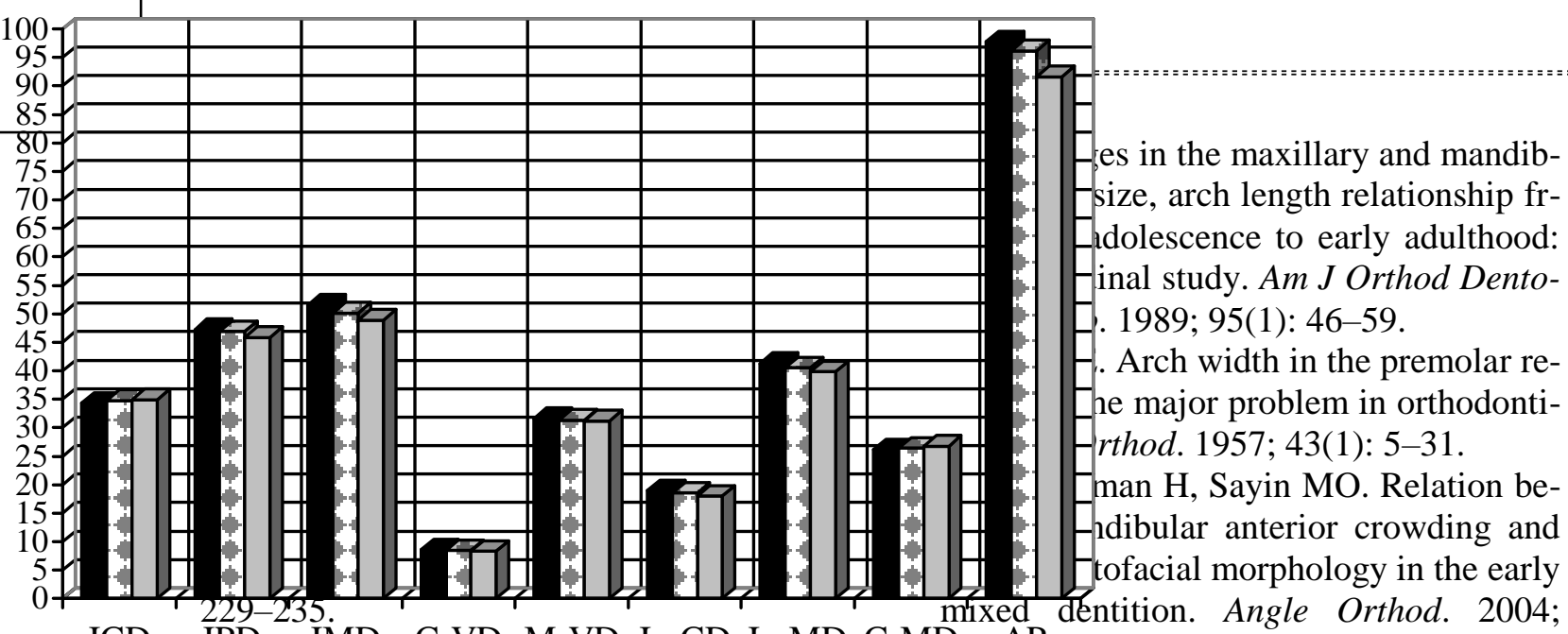

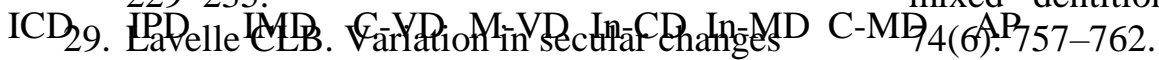

in the teeth and dental arches. Angle Orthod. 1973 ; 43(4): 412-421.

30. Bishara SE, Jakobsen JR, Treder JE, Stasi
33. Richardson ME. Lower arch crowding in the young adult. Am J Orthod Dentofac Orthop. 1992; 101(2): 132-137. 